\section{Success story}

\section{J. D. Ross}

Seed Dormancy in Grasses. By G. M. Simpson. Cambridge University Press: 1990. Pp.297. £35, $\$ 54.50$.

IF we are what we eat then, indeed, all flesh is grass. From the earliest days of agricultural society man has depended on the grass family for his bread, beer and beef. The Gramineae is one of the largest plant families with more than 600 genera and perhaps 10,000 species, found in virtually all ecosystems (including marine and Antarctic) and covering a greater percentage of the land surface than any other family. Such is the distinctiveness of grasses that even the botanically uninitiated can easily recognize this group by the characteristic vegetative structure and reduced floral parts. Eight genera contribute the cereal grasses while, on the other hand, seven of the worst weeds in the world are also grasses. There exists a massive scientific literature on the biology of the crops, pasture grasses and weeds about 350 species in all; of the others, the vast majority, we know very little beyond a rudimentary taxonomic description.

One factor contributing to the natural success of the Graminac is their superb adaptation to being grazed, cut, trampled and burned. Another important feature is their relatively large and aggressive reproductive output; they tend to be prolific in the production of mobile and invasive secds.

In the cercal growing regions of the world one of the most pernicious weeds is the wild oat, Avena fatua; the key to its success arguably being its dormancy mechanism which results in infestations lasting many years, even under the

\section{New in paperback}

- International Environmental Diplomacy edited by John E. Carroll concerns itself with the international policy aspects of environmental problems, their management and resolution. Published by Cambridge University Press, price $£ 12.95, \$ 24.95$

- From Earthscan comes Elephants, Economics and lvory by Edward Barbier, Joanne Burgess, Timothy Swanson and David Pearce. The authors set out to show how the careful mangement of elephants as a resource can best serve African interests. Price $£ 8.95$.

- Reprinted by Gordon and Breach is Lavoisier - The Crucial Year by Henry Guerlac which examines a key period in the career of AntoineLaurent Lavoisier, the chief architect of the chemical revolution. Price $\$ 27.00$.

- Neural Computing: An Introduction by R Beale and $T$. Jackson is aimed at computer science undergraduates and anyone interested in neural networks and artificial intelligence. Starting from basics, it goes on to cover all the most important approaches to the subject. Published by Hilger, price $£ 15.00$ cleanest of cultivation regimes. G. M. Simpson, the author of this somewhat anachronistic monograph, has spent much of his research career studying this phenomenon. This approach is unusual but successful, for here is a physiologist who knows the taxonomy of the family and sees the usefulness of such knowledge. The deeply researched wild oat is used as a model alongside reviews of the comparable knowledge on other species. Over a thousand references are cited in reviewing endogenous influences on dormancy and interactions with environmental factors. Many of these reports originated from the Weed Research Organization, now regrettably no longer operating, weeds of our crops being perhaps too near the market-place for British science.

As with other physiological systems the

\section{Highly prized molecule}

\section{Jim S. Owen}

Cholesterol Metabolism, LDL, and the LDL Receptor. By N. B. Myant. Academic: 1990. Pp. 465. £46.95, \$69.95.

Those who aspire to a Nobel prize, but who have yet to select their magnum opus, would do well to muse over this volume. No fewer than 14 laureates have chosen to study cholesterol, a molecule not only essential as a structural component of eukaryotic membranes and a precursor of steroid hormones and bile acids, but also an aberrant one because of its role in the cause or exacerbation of several diseases, most notably atherosclerosis. Cholesterol homeostasis at the cellular and molecular level is the theme of Myant's book, which in a sense charts the story and sequel of the most recent award, in 1985, to M. S. Brown and J. S. Goldstein who fittingly provide a foreword.

The journey begins with a guided tour through the maze of information on the regulation of $\mathrm{HMG}-\mathrm{CoA}$ reductase, the intracellular rate-limiting enzyme of cholesterol biosynthesis, at the level of both gene and protein. There is a diversion in the form of the biochemistry of acyl-CoA:cholesterol acyltransferase or ACAT - but only a brief one because this important sensor of a cell's unesterified cholesterol content remains poorly characterized, almost embarrassingly so when considered alongside, as here, the plethora of details on the two other key monitors - before we embark, at an ever increasing pace, into systematic and detailed descriptions of the structure and molecular genetics of the two principal proteins involved in delivering cholesterol to the cell: the low-density lipoprotein (LDL) receptor and its ligand, apoB-100, reductionist approach has yielded an impressive amount of information, but in bringing these data together we have failed to elucidate a general understanding. When this happens the timid researcher switches to another problem and the brave one moves into modelling. In the last section of this book there is an attempt to do just that: using Odum-style energy flow diagrams the author draws attention to the holistic nature of the physiology of the dormant seed. All in all, Seed Dormancy in Grasses provides a most useful case study with a balanced coverage and an optimistic attitude to the future, the latter being something I did not share until I read this book.

J. D. Ross is in the Department of Botany, University of Reading, Reading RG6 2AS, UK.

the major cholesterol carrier in human plasma. En route there are minor detours - to absorb relevant information on such supporting acts as the scavenger receptor, apoB-48, the LDL-receptor-relatedprotein (LRP), Lp(a) and modified LDL - many of which would constitute major holdups were it possible to include this year's literature. But the final route is not quite circular; homeostasis also demands the ability to return cellular cholesterol to the circulation and neither this, nor the importance of the HDL carrier system to the process, particularly the role of the prebeta-migrating HDL particles, are discussed.

The last decade has seen remarkable advances in the understanding of cholesterol transport and metabolism. Many illuminate other areas of cellular and molecular biology, including the functioning and recycling of cell-surface receptors, the concept of several different functional domains within a single polypeptide, and the control of expression of genes encoding inducible proteins. This book is an indispensable guide to these achievements and many people, myself included, will be grateful for its timely appearance: the scientific and clinical teachers of lipoprotein metabolism and familial hypercholesterolaemia for its comprehensive reviews of several complex issues; the multidisciplinary army of workers in the field, particularly those without training or experience in molecular biology; and the growing number of interested nonspecialists, including, for example, parasitologists who increasingly recognize that the cholesterol of pathogenic organisms is often an essential nutrient derived by receptor-mediated endocytosis of host lipoproteins. The chronicler of the next ten years of cholesterol metabolism would be well advised to begin now.

Jim S. Owen is in the Academic Department of Medicine, Royal Free Hospital School of Medicine, London NW3 2PF, UK. 